function. Overall, most were interested in safety information and to improve the safety, but the will to invest on safety was low.

Conclusions The care service chain has overall good motivation to improve the safety and fire safety of vulnerable people. However requirements of rescue service act did not materialise in assisted living as well as possible. There is apparent need of knowledge and vocational education material.

\section{EPIDEMIOLOGY OF BURNS AND SUBSEQUENT CARE SEEKING IN MARINGÁ, BRAZIL}

${ }^{1,2}{ }^{2}$ Anjni Patel, ${ }^{2}$ Nicole Toomey, ${ }^{2}$ Deena El-Gabri, ${ }^{2,3}$ Joao Ricardo Vissoci, ${ }^{2}$ Catherine Staton ${ }^{1}$ Emory University, Atlanta, GA; ${ }^{2}$ Duke University, Durham, NC; ${ }^{3}$ Faculdade Ingá, Maringá, Brazil

\subsection{6/injuryprev-2016-042156.799}

Background Like other injuries, the majority of burns (90\%) occur in low and middle-income countries (LMIC). However, burn epidemiology is highly variable between regions, with females having a higher prevalence in some areas. This projects aims to examine the demographics of burn patients and the proportion and characteristics of those who seek care.

Methods Injury and burn injury data was collected by survey on care seeking behaviour after injury in Maringá, Brazil between May and September 2015. Surveys compiled household demographics, then randomly selected one household member to provide lifetime injury history. Injuries due to burns were analysed by frequency and chi-square to describe the relationship between burns and care seeking with consideration to gender, occupation and injury severity, defined as immediate loss of normal functioning.

Results 2678 surveys were collected reporting 812 injuries including 120 burns. 86 (71.7\%) of the reported burn patients were women and half (55\%) were 18-55 years old. $31.4 \%$ of women were housewives and $32.7 \%$ of men were self-employed. Significantly more burn victims (39.2\%) did not seek care compared to non-burn injury victims $(9.66 \%, \mathrm{P}<0.001)$. Of the burn victims that did not seek care, $74.7 \%$ were female compared to $50 \%$ of the non-burn injury victims. Burn victims had a 7.8 $(\mathrm{P}<0.001)$ increased odds of not seeking care compared to road traffic victims. Most burn patients (90\%, equal for both sexes) reported no long-term disability from their burn.

Conclusions A disproportionate number of women are injured by burns in Maringá, similar to other LMIC likely due to gender roles. Of the women injured by burns, $40 \%$ did not seek care and almost a third of those women were severely injured, suggesting significant barriers to appropriate treatment. This study offers important information on a subset of burn victims with potentially severe injuries that are not accounted for due to the fact that they did not seek care.

\section{FIRE SAFETY TRAINING INTEGRATING INTO MEDICAL PERSONNEL STUDIES}

${ }^{1}$ Jaana Sepp, ${ }^{1}$ Gerli Liivet, ${ }^{2}$ Virve Sirrak, ${ }^{2}$ Piia Tint. ${ }^{1}$ Tallinn Health Care College, Estonia; ${ }^{2}$ Tallinn University of Technology, Estonia

10.1136/injuryprev-2016-042156.800

Background According to the statistics of the National Labour Inspectorate, an alarming number of deaths and serious fire accidents have taken place during the past 10 years in the health care institutions in Estonia. There is a special legislative act for insuring fire safety in these institutions, but it has proven to be insufficient. Each hospital and nursing home has to ensure their own safety. Therefore, the Fire Safety Training course has been implemented in Tallinn Health Care College for the future personnel of medical institutions as a method of raising awareness. It consists of an introductory training for future hospital employees and annual trainings held by hospitals. The introductory portion of the programme lies in simulation training and E-learning.

The aim of this study is to assess the effectiveness of the learning programme.

Material and methods The course is located in an online environment in which every employee goes through a number of topics followed by a test. Everyone who passes the test can print out a certificate as a confirmation of the theoretical knowledge acquired throughout the course. This programme was first used in 2014. The practical portion of the programme takes place at Tallinn Health Care College's simulation centre and includes patient evacuation practice, fire extinguishing simulations etc.

The effectiveness of the learning package was examined by comparing the results of different approaches on the programme with the participation of 70 nurses, that had undergone the usual fire safety training for 2 hours in their workplaces. The nurses were divided into 2 equal groups ( 35 people). The training took place for two days.

The first group began with a 2-hour lecture, followed by individual training in the E-learning environment and the simulation portion of the programme.

The second group began with a 2-hour lecture, directly followed by simulation, leaving individual training portion in the Elearning environment for last. In the first phase of the simulation portion it was necessary to extinguish a fire, the second was to ensure the proper evacuation of the patients. All of the action was filmed. The training ended with discussions, analysis and evaluating the activities recorded on video.

Results The results were better in the group that passed the Elearning course before entering simulation training, than for those who began their course with simulation training.

The students got the possibility to analyse important problems that may arise in real-life work situations.

Conclusions It is necessary to use the advanced training methods to decrease the number of fire related accidents and human losses.

\section{AN EVALUATION OF EMERGENCY MANAGEMENT OF SEVERE BURN (EMSB) COURSE IN BANGLADESH: A STRATEGIC DIRECTION}

${ }^{1,2}$ Animesh Biswas, ${ }^{1}$ Saidur Rahman Mashreky, ${ }^{1}$ Kamran UI Baset, ${ }^{1}$ Md Jahangir Hossain, ${ }^{1}$ Fazlur Rahman. ${ }^{1}$ Centre for Injury Prevention and Research, Bangladesh (CIPRB); ${ }^{2}$ Department of Public Health Sciences, Örebro University, Sweden

10.1136/injuryprev-2016-042156.801

Background Burn is major Public health problem in Bangladesh. Interplast Australia and New Zealand, Australian \& New Zealand Burn Association (ANZBA) and CIPRB come forward to help Bangladeshi physician to improve their burn management skill. ANZBA initiated EMSB training program for Bangladeshi physician in 2008. The study was designed to determine the effectiveness of EMSB programme in Bangladesh.

Methods A cross sectional survey was conducted among a randomly selected EMSB trained doctors. In-depth interviews (IDIs) and Focus Group Discussion (FGD) were conducted with faculties and organisers of the EMSB program. 